\title{
Reservoir refilling enhances growth and recruitment of an endangered remnant riverine fish
}

Zeb Tonkin, Jarod Lyon, David S.L. Ramsey, Nick R. Bond, Graeme Hackett, Kyne Krusic-Golub, Brett A. Ingram, and Stephen R. Balcombe

Abstract: Rapid increases in native riverine fish populations associated with trophic upsurge immediately following reservoir construction are well documented. Repeated upsurge periods and extended benefits to populations are, however, less understood. We used sclerochronology to investigate fish growth and netting surveys to estimate recruitment and abundance of a lacustrine population of an Australian riverine fish, the Macquarie perch (Macquaria australasica) in Lake Dartmouth. Record low inflows from 1997 to 2008 caused the reservoir to shrink to its lowest volume since construction. Refilling began in 2008, reaching $99 \%$ capacity in 2013 . We hypothesized that fish growth, recruitment, and abundance would increase in response to the refilling of the lake, reproducing a similar response to the initial filling period. Our findings supported this hypothesis. Macquarie perch growth, recruitment, and abundance were enhanced during the refilling of Lake Dartmouth. Growth, best explained by the effects of dam height, change in dam height, temperature (and their interactions), and recruitment, were highest during the first years of refilling when lake levels and temperatures were low. We propose one or a combination of varying levels of intraspecific competition (low during initial filling and high following population expansion) and improved riverine conditions for reproductive success as the most plausible explanation. Our results suggest extended periods of low lake levels followed by rapid inundation events are likely to enhance recruitment and population growth opportunities for this species. While reservoir construction in general impacts negatively on native fish populations, the potential to offset these impacts for conservation management purposes should be considered.

Résumé : Les augmentations rapides de populations de poissons de rivière indigènes associées à la poussée trophique qui suit immédiatement la construction d'un réservoir sont bien documentées. La compréhension de périodes de poussée trophique successives et de leurs avantages pour les populations demeure toutefois plus limitée. Nous avons utilisé la sclérochronologie pour étudier la croissance des poissons et des relevés au filet pour estimer le recrutement et l'abondance d'une population lacustre d'un poisson de rivière australien, la perche de Macquarie (Macquaria australasica) dans le lac Dartmouth. Des débits entrants d'une faiblesse record de 1997 à 2008 ont fait diminuer le volume du réservoir jusqu'au point le plus bas enregistré depuis sa construction. Le nouveau remplissage a débuté en 2008, pour atteindre $99 \%$ de la capacité du réservoir en 2013. Nous avons postulé que la croissance, le recrutement et l'abondance des poissons augmenteraient en réponse à ce nouveau remplissage du lac, une réaction semblable à celle observée durant le remplissage initial. Nos constatations appuient cette hypothèse. La croissance, le recrutement et l'abondance des perches de Macquarie ont augmenté durant le nouveau remplissage du lac Dartmouth. La croissance, qu'expliquent le mieux les effets de la hauteur du barrage, des changements de cette hauteur et de la température (et leurs interactions), ainsi que le recrutement étaient à leur plus fort durant les premières années du nouveau remplissage, quand les niveaux et les températures du lac étaient faibles. Nous proposons que les variations du degré de concurrence intraspécifique (faible durant le remplissage initial, plus élevé après l'expansion de la population) et (ou) l'amélioration des conditions fluviales nécessaires au succès de reproduction constituent l'explication la plus plausible. Nos résultats donnent à penser que de longues périodes de faibles niveaux du lac suivies par des inondations rapides sont susceptibles d'accroître les possibilités de recrutement et de croissance de la population pour cette espèce. Si, en général, la construction de réservoirs a une incidence négative sur les populations de poissons indigènes, la compensation possible de ces impacts aux fins de gestion et de conservation devrait être prise en considération. [Traduit par la Rédaction]

\section{Introduction}

The construction of large dams and subsequent creation of reservoirs has been a major driver of reductions in the range and abundance of native riverine fishes globally. The detrimental impacts of inundating former habitats, downstream flow alteration, and barriers associated with reservoir construction are well documented (Poff et al. 2007; Lintermans 2012; Mims and Olden 2013), yet the potential enlancement of native fish populations within ог upstream of reservoirs has received very little attention (e.g., Ebner et al. 2011). Continued human population growth and

Received 14 February 2014. Accepted 25 August 2014.

Paper handled by Associate Editor Yves Prairie.

Z. Tonkin. Arthur Rylah Institute for Environmental Research, Department of Environment and Primary Industries, Heidelberg, Victoria, 3084, Australia; Australian Rivers Institute, Griffith University, Nathan, Qld 4111, Australia.

J. Lyon, D.S.L. Ramsey, and G. Hackett. Arthur Rylah Institute for Environmental Research, Department of Environment and Primary Industries, Heidelberg, Victoria, 3084, Australia.

N.R. Bond and S.R. Balcombe. Australian Rivers Institute, Griffith University, Nathan, Qld 4111, Australia.

K. Krusic-Golub. Fish Aging Services Pty Ltd., Queenscliff, Victoria, 3223, Australia.

B.A. Ingram. Fisheries Victoria, Department of Environment and Primary Industries, Alexandra, Victoria, 3714, Australia.

Corresponding author: Zeb Tonkin (e-mail: Zeb.Tonkin@depi.vic.gov.au). 
subsequent water demands dictate that large reservoirs will be a permanent component of many freshwater ecosystems. As such, there is an imperative to identify any conservation benefits these constructed habitats might provide and to identify specific management strategies that will preserve or enhance these benefits into the future.

In addition to the social benefits of reservoirs (see Baxter 1977; Ebner et al. 2011), the provision of permanent and often productive lacustrine environments can present benefits that enhance fish populations. Such opportunities are most frequently reported for populations of generalist or non-native lacustrine species (e.g., Kruk and Penczak 2003) or the establishment of recreationally important species through stocking (e.g., Cowx 1998; Cowx et al. 1998; Hunt et al. 2010). Nevertheless, the impounded water of reservoirs can also provide benefits to remnant riverine fish species (Irz et al. 2006; Ebner et al. 2011; Lintermans 2012). Examples include paddlefish (Polyodon spathula) in the United States (Paukert and Fisher 2001; Scarnecchia et al. 2009) and golden galaxias (Galaxias auratus) (Hardie et al. 2007, 2013) and Macquarie perch (Macquaria australasica) (Cadwallader 1981; Appleford et al. 1998) in Australia.

Riverine fish populations occupying new reservoirs often exhibit immediate increases in abundance and production, generally as a result of one or a combination of mechanisms relating to resource availability. The most documented and well understood is that of trophic upsurge, whereby nutrient release from inundated terrestrial vegetation and soils increase primary production, which is transferred to higher trophic orders, including fish (Grimard and Jones 1982; Robarts et al. 1992; Hendrickson and Power 1999; Albrecht et al. 2009). This period can also provide additional prey resources such as terrestrial invertebrates (e.g., Cadwallader and Douglas 1986), as well as increase the availability of essential habitats such as spawning substrate (e.g., Hardie 2013). Such rapid increases in resource availability are likely to result in immediate reductions in intraspecific competition, a common factor governing density dependence and the regulation of fish populations (Jonsson et al. 1998; Lorenzen and Enberg 2001; except see Lobón-Cerviá 2014). These mechanisms mirror the increased production from seasonal floodplain inundation (the socalled "flood pulse advantage"; Bayley 1991).

However, unlike the seasonally recurrent pulse of production occurring in tropical floodplain rivers, many of the benefits that reservoirs provide to remnant riverine species are short-lived. Lacustrine trophic upsurge generally lasts little longer than a decade, being followed by a period of trophic depression (Geraldes and Boavidav 1999) and subsequent decline in fish abundance and production (Hendrickson and Power 1999). Nevertheless, repeated upsurge periods and subsequent population responses by remnant riverine fish are possible. Scarnecchia et al. (2009) reported paddlefish populations increasing dramatically in response to the refilling of Lake Sakakawea on the Missouri River, almost 30 years after the initial filling phase.

This study investigates the response of Macquarie perch, a medium-sized freshwater fish species native to southeastern Australia, to the refilling of a large reservoir. The species has undergone declines in distribution and abundance to the extent that it is now listed as nationally endangered under the Environmental Protection and Biodiversity Conservation Act 1999 (Commonwealth) (Lintermans 2007; Hunt et al. 2011). Being a riverine species, the construction of dams that act as barriers to movement and modify downstream river flows and temperatures are thought to be a major reason for their decline (Ingram et al. 2000). While Macquarie perch are naturally riverine fish, the species established strong populations in several large irrigation reservoirs where they have access to suitable inflowing riverine habitat for spawning (Cadwallader 1981; Appleford et al. 1998). Lacustrine environments have been demonstrated to provide both refuge (Ebner et al. 2011) and feeding opportunities by providing a rich supply of terrestrial and aquatic invertebrates, particularly during the filling periods of reservoirs (Cadwallader and Douglas 1986)

Jacustrine populations of Macquarie perch typically exhibit declines in abundance 5-10 years after initial filling (Harris and Rowland 1996; Hunt et al. 2011), which is in accordance with the boom-bust pattern of productivity in newly formed reservoirs. Nevertheless, some impoundments still retain substantial stocks of Macquarie perch, including Lake Dartmouth (Hunt et al. 2011) and the Cotter Reservoir (Ebner et al. 2011), albeit in reduced abundances to initial filling periods. As such, there is potential for these populations to be enhanced by replicating the events of the initial filling period, as demonstrated by paddlefish in the Northern Hemispliere (Scarnecchia et al. 2009). We investigate the response of Macquarie perch to the refilling of Lake Dartmouth in the wake of the "millennium" drought, which persisted from 1997. to 2007 and was associated with record low stream flows in southeastern Australia (Murphy and Timbal 2008). The population was reported to have undergone reduced condition and spawning performance (Ingram and Gooley 1996; Gray et al. 2000) and a subsequent decline in abundance (Hunt et al. 2011) during the postfilling phase of the lake. Therefore, we hypothesize that growth, recruitment, and subsequent population size would increase in response to the refilling of the lake.

\section{Methods}

\section{Study site}

Lake Dartmouth $\left(36^{\circ} 30^{\prime} \mathrm{S}, 147^{\circ} 30^{\prime} \mathrm{E}\right)$ is the largest freshwater impoundment in southeastern Australia's Murray-Darling Basin (Fig. 1). The lake, an irrigation storage (primarily) that impounds the Milla Mitla River, has at full capacity a surface area of 6380 ha and stores almost $4000000 \mathrm{ML}$ of water (Gray et al. 2000). The construction of the dam was finalized in 1979, after which time the lake took 11 years to reach full capacity (initial filling phase; 1979-1990; Fig. 2). The following 17 years consisted of initially stable water levels held above $90 \%$ capacity, followed by a gradual reduction of levels (stable or draw-down period; 1991-2007) due to the "millennium" drought throughout southeastern Australia (Bond et al. 2008). During mid-2008, the lake began a rapid refilling phase, inundating regrowth of both native and exotic vegeta. tion. This refilling phase continued into mid-2013, when the lake reached 99\% capacity. Water level fluctuation of Lake Dartmouth generally follows the seasonal rainfall pattern of the region. Specifically, the highest rainfall usually occurs in winter and spring periods (June-November), resulting in the highest inflows and rising lake levels. Conversely, summer periods (December-February) are characterized by lower rainfall, reduced inflows, and receding lake levels. The latter is also exacerbated by increased irrigation releases over summer.

While the creation of Lake Dartmouth is believed to have caused the disappearance of Macquarie perch from riverine habitats downstream of the reservoir (Department of Primary Industries, unpublished data), a population established within the lake. While numerous unregulated tributaries flow into Lake Dartmouth, the largest, the Mitta Mitta River, is the primary spawning area used by Macquaric perch during their annual spring spawning migration from the lake (Douglas et al. 2002; Tonkin et al 2009).

\section{Age and growth}

Sclerochronology, using otolith increment widths, was used to investigate temporal patterns in annual growth rates of Macquarie perch given the relationship between otolith growth and 
Fig. 1. Map of Lake Dartmouth including position of dam wall and major tributaries. Mitta Mitta River is the primary tributary for Macquarie perch spawning.

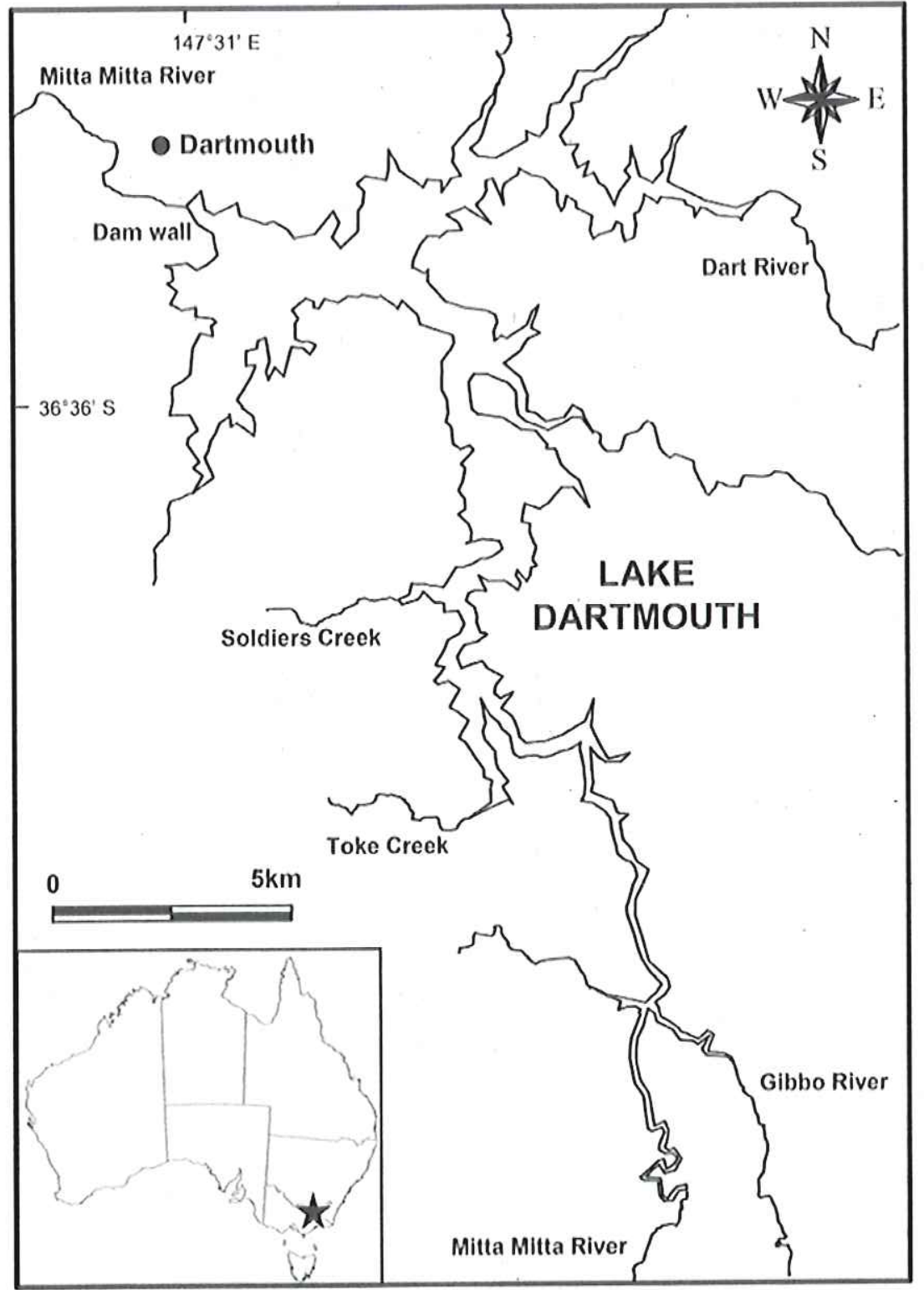

somatic growth (otolith radius versus fish length; see online Supplementary data, Fig. $\left.S 1^{1}\right)$. This technique has been utilized to investigate fish growth responses to a range of environmental drivers, including resource availability and climate change (e.g., Morrongiello et al. 2011a). Transverse sections of sagittal otoliths have also been used to estimate ages of Macquarie perch up to 17 years of age (Douglas et al. 2002; Hunt et al. 2011) and used to estimate ages and growth for the closely related percichthyid, golden perch (Macquaria ambigua) (Anderson et al. 1992; Stuart 2006; Morrongiello et al. 2011a).

Macquarie perch sagittal otolith samples were collected from fish that had died during netting surveys or broodstock collection. The most recent samples ( $n=144$ ) were from fish collected during population surveys conducted as part of this study (see below) and broodstock collection between 2008 and 2012. Archival collections of Fisheries Victoria (Department of Environment and Primary Industries) were sourced from fish collected during netting surveys of the lake in $1990(n=72)$ and $1997(n=26)$. All Macquarie perch collected were measured for total length (TL, nearest millimetre), and their sagittal otoliths were removed, dried, and stored in a paper envelope before embedding in epoxy resin. Otoliths were thin-sectioned through the primordium across the transverse plane, mounted on a glass slide with thermoplastic cement, and polished using $3 \mu \mathrm{m}$ lapping film to remove major scratches.

Otolith sections were independently labelled and photographed at 20x magnification using a dissecting microscope illuminated with

ISupplementary data are available with the article through the journal Web site at http://nrcresearchpress.com//doi/suppl/10.1139/cjfas-2014 0081. 
Fig. 2. Mean monthly water levels (solid line; metres above sea level) of Lake Dartmouth from 1979 to 2012 , including the periods of the initial filling, stable-declining, and refilling phases of the lake. An indicator of annual temperature variability is presented as degree montlis (grey bars), calculated as the cumulative mean monthly air temperature of Dartmouth township for each year.

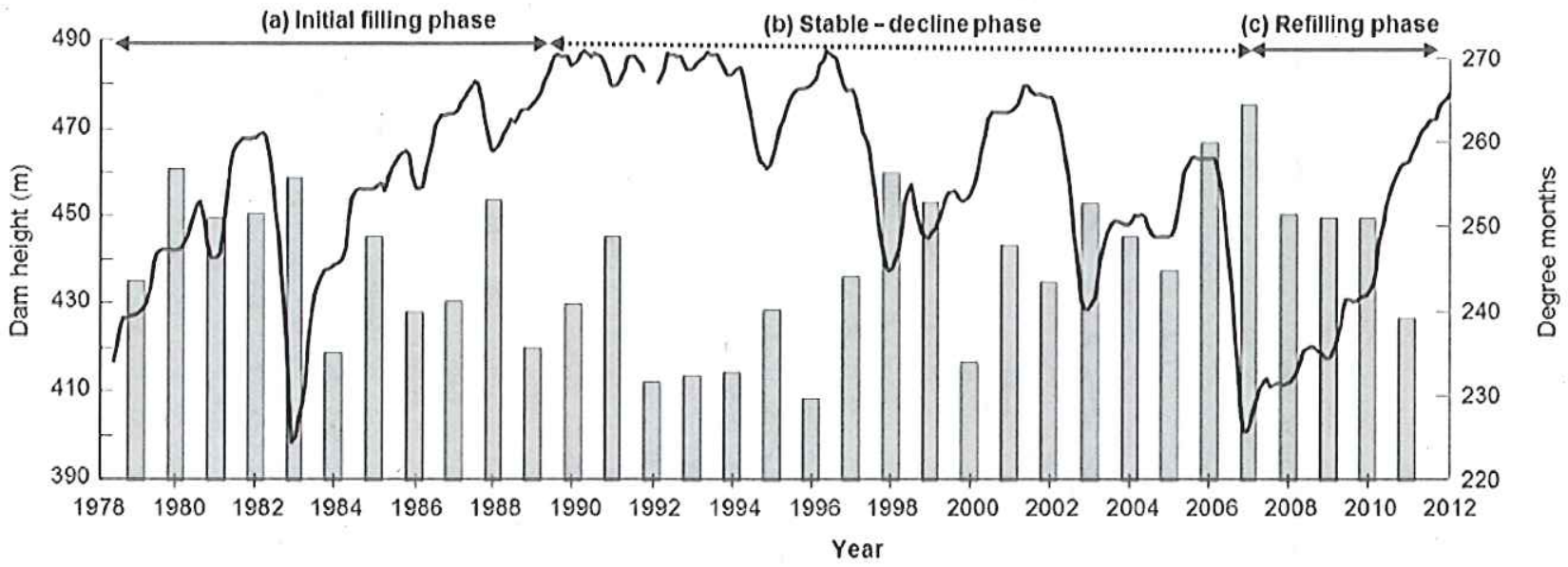

Table 1. Description of variables used in mixedeffects modelling of Macquarie perch otolith growth.

\begin{tabular}{ll}
\hline Variable & Description \\
\hline ID & Individual fish number \\
Year & Macquarie perch growth year (1 November - 31 October) \\
$\begin{array}{l}\text { Age } \\
\text { Fam_phase }\end{array}$ & Whether the growth year is within the initial filling (1: 1979-1991), steady-receding (2: 2002-2007), \\
& or refilling (3: 2008-2013) period \\
Dam_height & Water level (metres above sea level) at the end of the given growth year \\
Height change & Change in dam height at the end of the given growth year from previous \\
$\begin{array}{l}\text { Degree_months* } \\
\text { Inundation }\end{array}$ & $\begin{array}{l}\text { Cumulative monthly mean air temperature for Dartmouth township of the given growth year } \\
\text { Categorical value based on time (years) since inundation of littoral zone: } 1=<1 ; 2=1-2 ; 3=3-5 ; 4=>5 \text { years since inundation }\end{array}$
\end{tabular}

'Nearby township air temperature used as a proxy for water temperature given the lack of historical records of dam water temperatures records.

transmitted light. Annuli, defined as a pair of translucent and opaque zones, were counted without information on fish size or sampling date to estimate an individual's age in years (e.g., Hunt et al. 2011).

The width of each annuli was then used to reconstruct annual growth. Annuli were marked at the start of each opaque zone on a transect that ran from the primordium to the distal edge on the ventral side adjacent to the sulcus. This transect was selected because it showed minimal deviation in its growth axis. Older specimens, which did display any such change in growth axis, were countered by adjusting the transect angle from the point of deviation. The edge type of each otolith section was classified as new (opaque), intermediate (narrow translucent), or wide (wide translucent), based on the optical state of the outermost zone. The marginal state analysis, when compared with the samples collection date, revealed that the transition from wide (suggesting that there should be a zone about to form) to new edge types occurred in samples collected from October to early December. This period coincides with the peak spawning period of the species (Douglas et al. 2002; Tonkin et al. 2009). As a result, we estimated each annuli width to represent the individuals' growth from 1 November to 31 October. This also enabled zone counts to be adjusted to more accurately back-calculate birth year (zone counts were increased by one if the otolith had been classified as having a wide marginal state).

Population change and recruitment strength

Annual netting surveys of Lake Dartmouth were used to assess changes in abundance, size structure, and recruitment strength of Macquarie perch. The methods used were comparable to those used by Douglas et al (2002) to survey the lake in 1999 and 2000. Briefly, surveys were undertaken over a 5-day period between
February and April (late summer - early autumn). Between six and ten gill nets (25 m length; $2 \mathrm{~m}$ drop; 50.8 to $112.5 \mathrm{~mm}$ stretched mesh) were set for one overnight period (1800-0800; checked every $2 \mathrm{~h}$ ) in the three regions of the lake (Mitta Mitta arm, Dart River arm, and Eight-mile - main basin; Fig. 1). The same number of single wing fyke nets were also set for one overnight period in each region of the lake to collect younger cohorts of fish not selected by gill nets. In consideration of their conservation status, most Macquarie perch were released after being weighed and measured for TL. Otoliths were opportunistically collected from only those fish that had died in the nets.

\section{Analysis}

A standard nonlinear regression model (Gompert\%) of length $I_{\times}(\mathrm{mm})$ at age $X$ (years) was constructed from all aged fish to enable estimates of age from length data collected during netting surveys. Specifically:

$$
\text { Gompert\%: } I_{x}=I_{\infty} \mathrm{e}^{\mathrm{e}^{1-k x-M / X}}
$$

where $L_{x}$ is the length at age $X, L_{s}$ is the asymptotic length, $b$ is the instantaneous growth rate, and $M$ is the inflection point of the curve (years).

Mixed effects linear models (LMM) were used to investigate otolith-derived measures of annual growth (from the repeated growth measures for individual fish) in response to a suite of predictors (lable 1). Predictors were either related to covariates, which are consistently reported to have strong influences on fish growth (e.g., fish age and temperature; Tonkin et al. 2008; Morrongiello et al. 2011a), or were hydrologic variables associated 
Fig. 3. The relationship between total length $(\mathrm{mm})$ and estimated age (years) for Macquarie perch predicted by the Gompertz growth model. $\Lambda$ ge data from direct reading of otoliths is indicated by black crosses $(x)$.

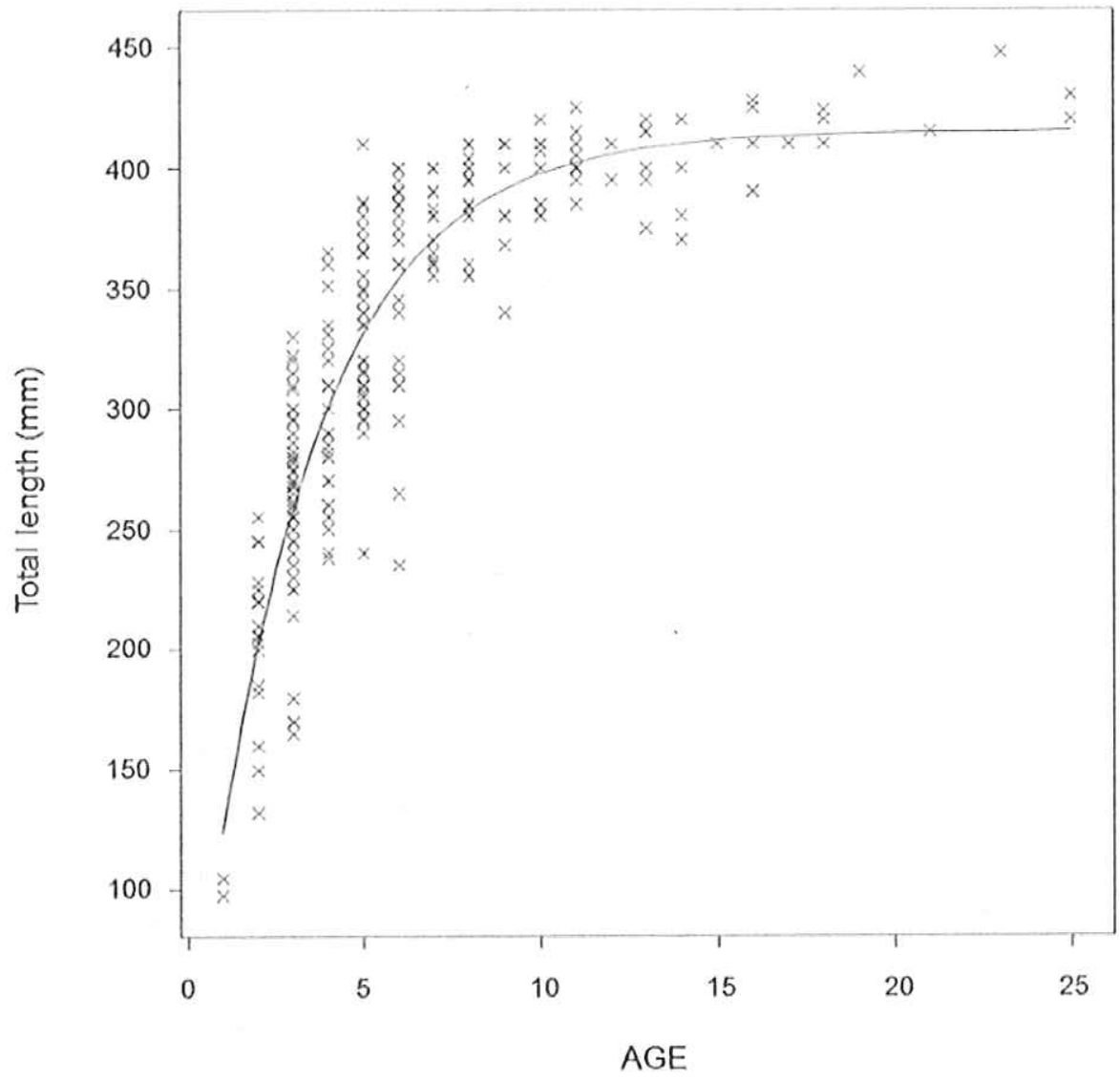

Fig. 4. Cohort frequency (birth year) of all Macquarie perch aged in the study. Black Iriangles indicate period of tish sampling and numbers of fish collected.

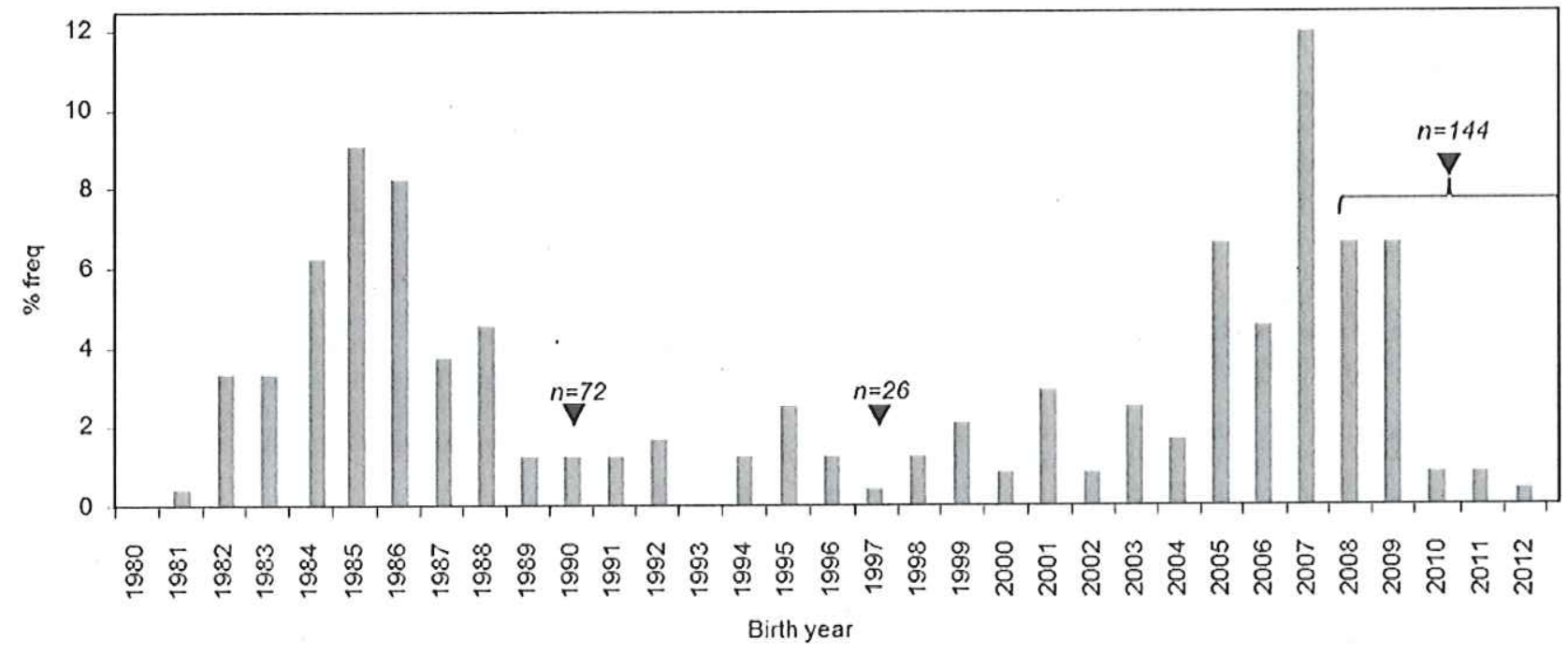

with testing our predictions of growth responses to the lake filling (specifically, dam phase, water level, change in water level, and years since littoral inundation; Table 1$)$. $\Lambda$ complete additive model was first fitted to the data, which included all fixed effects, including $\Lambda$ ge, as well as random effects of fish ID (random intercept for each individual), Age within fish ID (random slopes for age for each individual), and Year (random in tercept for Year). Specifically: 
Fig. 5. Macquarie perch annuli width (mean \pm SD) for each year (age) of growth.

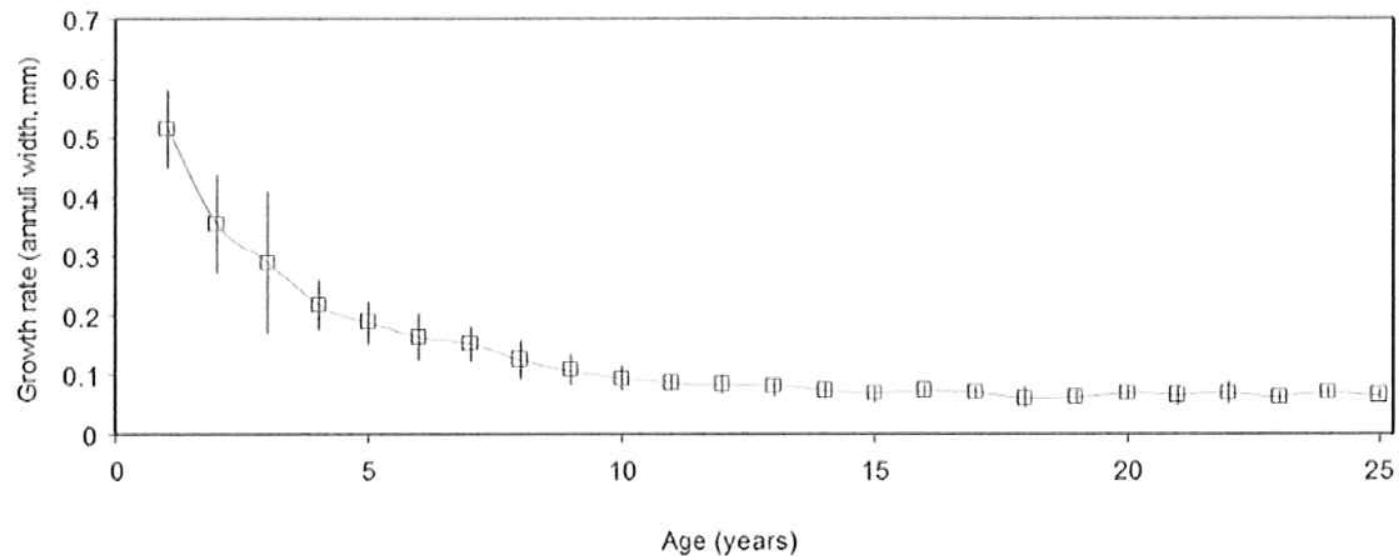

Fig. 6. The predicted first year growth (annuli width, mm) of Macquarie perch during the initial filling (phase 1; 1979-1990), stable-declining (phase 2; 1991-2007); and refilling (phase 3: 20082013) periods of Lake Dartmouth.

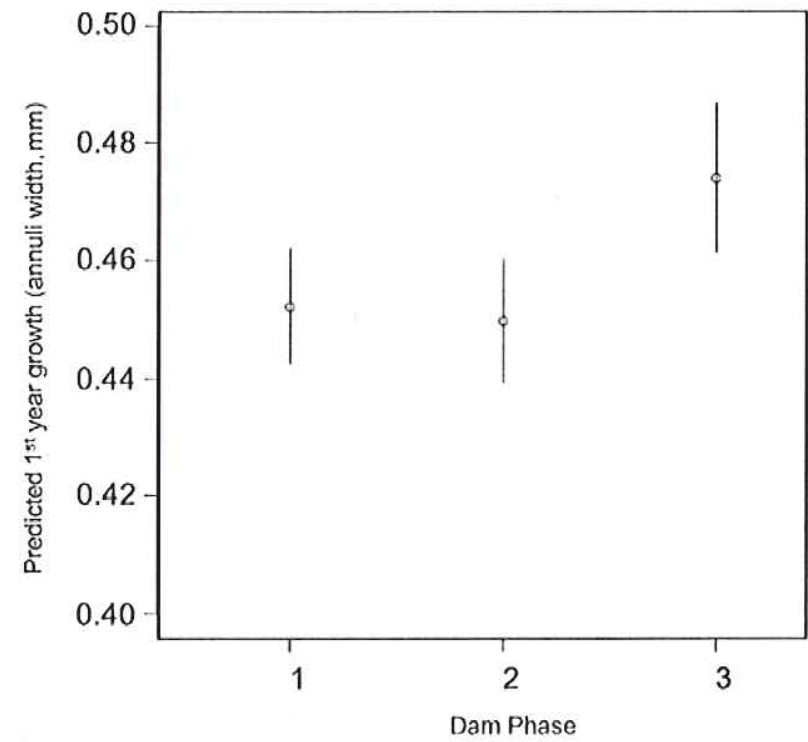

Growth $\sim$ Age + I $\left(\right.$ Age $\left.^{2}\right)+$ Dam_height + height change + Dam age + Degree months + Dam phase + Inundation + STDEV_dam_height $+(1 \mid$ ID $)+(0+$ Age $\mid$ ID $)+(1 \mid$ Year $)$

This randomeffects structure allowed each individual fish to have its own random age-growth relationship (correlated slopes and intercepts) as well as allow for a separate random effect of year of observation. The latter random effect was uncorrelated with the age-growth random effects. Hence, we were not interested in the effects of observation year per se, but wanted to account for random year-to-year variation in growth relationships that may be due to unmeasured effects of observation year. The residuals of this model exhibited considerable curvature, indicating the strong effects of Age on growth. The quadratic of Age $\left(\mathrm{Age}^{2}\right)$ was included to remove this curvature. Initial modelling concentrated on selecting the appropriate random-effects structure using fish ID (random intercept), fish Age (random in- tercept and slope), and observation Year (random intercept uncorrelated with ID) using the complete addlitive fixed effects structure. $\wedge$ variety of fixed effects structures were then examined to investigate the following:

(i) whether growth rates differed among the three filling periods of the dam (Fig. 2) using a single fixed effect of dam phase (and also including $\Lambda \mathrm{ge}+\Lambda \mathrm{ge}^{2}$ ) and

(ii) whether any differences in growth rates between dam phases could be explained by one or a combination of four annual environmental covariates of hydrology and temperature (Table 1).

The relative support for each of the random and fixed-effects models was assessed using Akaike's information criterion (AIC), corrected for small sample size (AIC $C_{c}$ ) (Burnham and Anderson, 1998). $\mathrm{AIC}_{\mathrm{c}}$ values were rescaled as differences between each model and the model with the lowest $\mathrm{AIC}_{\mathrm{c}}$ value. All linear mixedeffects models were fitted using the lmer function within the package lme4 (Bates et al 2011) using the R statistical programming environment (R Development Core Team 2005).

Macquarie perch catches in gill nets (CPUE $=$ number of fish per net) were used to investigate annual changes in abundances (fyke net data was excluded because of very low numbers of fish collected). Macquarie perch CPUI: for each year were compared using a generalized linear model (GLM) using a Poisson distribution and logarithmic link function because of the non-normal distribution of catch data. While the details of catch data used in the analysis was not available for the data collected during 1999-2000 (Douglas et al. 2002), mean numbers of fish per net were plotted in figures enabling some reference to catches of the recent surveys.

Individual cohorts of Macquarie perch were identified using length data, and subsequent estimated ages were predicted using the aforementioned Gompertz model (generated from the population's length at age data). Both length and predicted ages were then assessed using frequency histograms to back-calculate yearclass strength during annual sampling from 2010 to 2013.

\section{Results}

Age and growth

A total of 236 Maccuarie perch, ranging in size from 98 to $448 \mathrm{~mm}$ Tl, were aged during this study. The oldest fish were estimated to be 26 years of age and were 440 and $420 \mathrm{~mm} \mathrm{TL}$, respectively (lig. 3). The predicted relationship between age and length of Macquarie perch from the Gompertz model showed rapid fish growth up until 6 years of age $(\sim 350 \mathrm{~mm} \mathrm{TL})$, followed by stable growth thereafter (Fig. 3). The parameter estimates from this model are $L_{\infty}=410.65 ; b=0.3946$; and $M=1.086$. 
Table 2. Results of the model selection procedure for 11 models comparing the effects of water level and temperature variables on Macquarie perch growth in Lake Dartmouth.

\begin{tabular}{|c|c|c|c|c|c|c|}
\hline No. & Model parameters & $\mathrm{AIC}$ & $\Lambda \mathrm{IC}$ & df & $\triangle \mathrm{AIC}_{c}$ & Likelihood \\
\hline 7 & Dam_height + height change + degree_months* & -784.294 & -784.036 & 13 & 0.000 & 0.680 \\
\hline 6 & Dam height + degree_months ${ }^{\dagger}$ & -782.364 & -782.236 & 9 & 1.800 & 0.276 \\
\hline 5 & Dam_height + height changet & -777.353 & -777.226 & 9 & 6.810 & 0.023 \\
\hline 1 & Dam_height & -777.145 & -777.065 & 7 & 6.970 & 0.021 \\
\hline 10 & Degree_months + height change + inundation ${ }^{*}$ & -769.494 & -768.833 & 21 & 15.203 & 0.003 \\
\hline 8 & Inundation + height changet & -764.064 & -763.805 & 13 & 20.230 & 0.000 \\
\hline 4 & Degree_months & -758.1608 & -758.082 & 7 & 25.954 & 0.000 \\
\hline 2 & Heightchange & -757.376 & -757.297 & 7 & 26.738 & 0.000 \\
\hline 9 & Degree_months + heightchanget & -757.063 & -756.936 & 9 & 27.100 & 0.000 \\
\hline 11 & Degree_months + inundation ${ }^{\dagger}$ & -757.152 & -756.893 & 13 & 27.143 & 0.000 \\
\hline 3 & Inundation & -756.858 & -756.730 & 9 & 27.305 & 0.000 \\
\hline
\end{tabular}

Note: $\Lambda \mathrm{IC}, \Lambda$ kaike's information criterion (subscript c, corrected for small sample size); $\Delta \mathrm{AIC}_{\mathrm{c}}$, difference in $\mathrm{AIC}_{\mathrm{c}}$ between this model and the model with the lowest AIC

"Main effects plus all two-way and three-way interactions.

IMain effects plus all two-way interactions.

Back-calculated spawning years using the entire otolith sample set idlentified cohorts during all but 2 years between 1980 and 2012 (Fig. 4). The greatest proportion of fish in the sample set was from the 2007,1985 , and 1986 year classes $(12 \%, 9 \%$, and $8 \%$ of the samples, respectively). This expansive range of cohorts and fish longevity enabled a complete reconstruction of growth since the early filling phase of the reservoir. Importantly, otolith growth in response to age reflected the Gompertz growth model predictions (length at age), where annuli widths rapidly decreased until 6 years of age, after which widths were consistently narrow (Fig. 5). Growth, as indicated by both otolith growth and length at age data, was most variable for younger cohorts of fish (Fig. 3)

Model selection using $\mathrm{AIC}_{\mathrm{c}}$ on four random effects models, using a complete additive fixed-effects structure, identified almost indistinguishable support for two models that included a random age-growth relationship for each individual (random age slopes and intercepts for each individual with no correlation between slope and intercept) and a second model that included an additional random intercept for Year $\left(\mathrm{AIC}_{\mathrm{c}}=-680.0441\right.$ and 679.0312, respectively). Hence, we selected the model with the simpler random effecis structure (specified in Imer as (1| ID) $+(0+\Lambda$ ge $\mid$ ID)) that just included the (uncorrelated) random age slopes and intercepts for each individual and used this for all subsequent analysis.

The first fixed-effects model used Age, Age $^{2}$, and dam phase to determine whether Macquarie perch growth rates differed among the three filling stages of the dam. All three fixed effects were significant factors in predicting Macquarie perch growth (LMM; $p<0.001, p<0.001$, and $p<0.01$, respectively). While age was the overarching factor determining Macquarie perch growth, model predictions indicated growth during the refilling period of the dam (2008-2013) was significantly higher than growth during both the initial filling (1979-1990) and stable-declining periods (1991-2007; Iig. 6). Surprisingly, Macquarie perch growth during the initial filling phase and stable-declining periods were similar.

lurther analyses of 11 fixed-effects models representing one or a combination of the environmental covariates indicated models 7 and 6 provided the best explanations of growth rates relative to other models (Table 2). Hence the effects of dam height, change in dam height, temperature (degree months), and their interactions were the covariates considered the most important in explaining variations in growth rates. Predictions from the model indicated the highest growth rates of Macquarie perch to occur during years of low lake levels (liigs. 7a, 7b,7c). During such periods, lower temperatures and dropping water levels contribute to the highest growth. The lowest growth was predicted to occur during years of high lake levels, lower temperatures, and dropping water levels (Figs. 7g, 7h, 7i), which reflect those conditions most frequent during the stable-declining period).
Population change and recruitment strength

A total of 244 Macquarie perch were collected during the netting surveys from 2010 to 2013, with gill nets accounting for more than $81 \%$ of the catch $(n=198$ and $n=44$ in gill and fyke nets, respectively). Macquarie perch were collected in very low numbers during the first annual survey during 2010 (only six fish collected in gill nets), with CPUE values slightly lower than those recorded by Douglas et al. (2002) during 1999-2000 (lig. 8). $\Lambda$ dramatic increase in the numbers of Macquarie perch captured in the lake then followed, with significantly greater numbers of fish recorded in 2011, 2012, and 2013 than in 2010 (GLM; $p<0.05$, $p<0.01$, and $p<0.01$, respectively; Fig. 8 ). While Macquarie perch CPUli continued to increase after 2011, the rate of change between each year was low, with no significant difference in CPUE detected among the last 3 years of surveys.

The size of Macquarie perch collected using all methods from 2010 to 2013 ranged from 95 to $440 \mathrm{~mm}$ TL. (Fig. $9 a$ ). Of the few fish collected in 2010 , the majority $(\sim 68 \%)$ were juveniles collected in fyke nets: $<140 \mathrm{~mm}$ TL. These fish, being primarily $1+$ and $2+$ fish (as predicted by the Gompertz growth curve and several directly aged individuals) belonged to the 2007 and 2008 cohorts (Fig. 9a). Length frequencies of catches in subsequent years tracked several cohorts of juvenile fish to the point where catches of Macquarie perch in the final year of sampling had length ranges of 240 $320 \mathrm{~mm}$ TT. These catches were dominated by the 2007 and 2008 cohorts, with 2006 and 2009 also strong year classes (Fig. 9). Lower proportions belonged to cohorts beyond 2009.

\section{Discussion}

This study has demonstrated that remnant riverine fish populations occupying large reservoirs can be re-enhanced beyond the early periods of trophic upsurge associated with initial reservoir filling. Macquarie perch populations displayed increased growt and recruitment strength during the refilling of lake Dartmouth 29 years after its construction and 17 years after the initial filling phase concluded. Importantly, the results demonstrate that fishes of conservation value such as the Macquarie perch can persist or be enlanced in large irrigation reservoirs.

Macquarie perch growth and recruitment strength did, as hypothesized, increase during the recent refilling period of lake Dartmouth. This is likely a result of the increased availability of prey, generated by the inundation of newly revegetated littoral areas, enlancing lower trophic order productivity (e.g., Hendrickson and Power 1999; Albrecht et al. 2009) and the provision of terrestrial invertebrates (e.g., Cadwallader and I)ouglas, 1986). Our findings are consistent with those of Scarnecchia et al. (2009), who reported stronger year classes and faster growth of paddlefish 
Fig. 7. The predicted first year growth (annuli width, $\mathrm{mm}$ ) of Macquarie perch under different combinations of dam height (low $=410 \mathrm{~m}$, medium $=458 \mathrm{~m}$, high $=486 \mathrm{~m}$ ); water level change (height change: dropping $=-46 \mathrm{~m}$, stable $=0 \mathrm{~m}$, rising $=26 \mathrm{~m}$ ); and tenperatures $($ degree months calculated as cumulative mean monthly temperature).
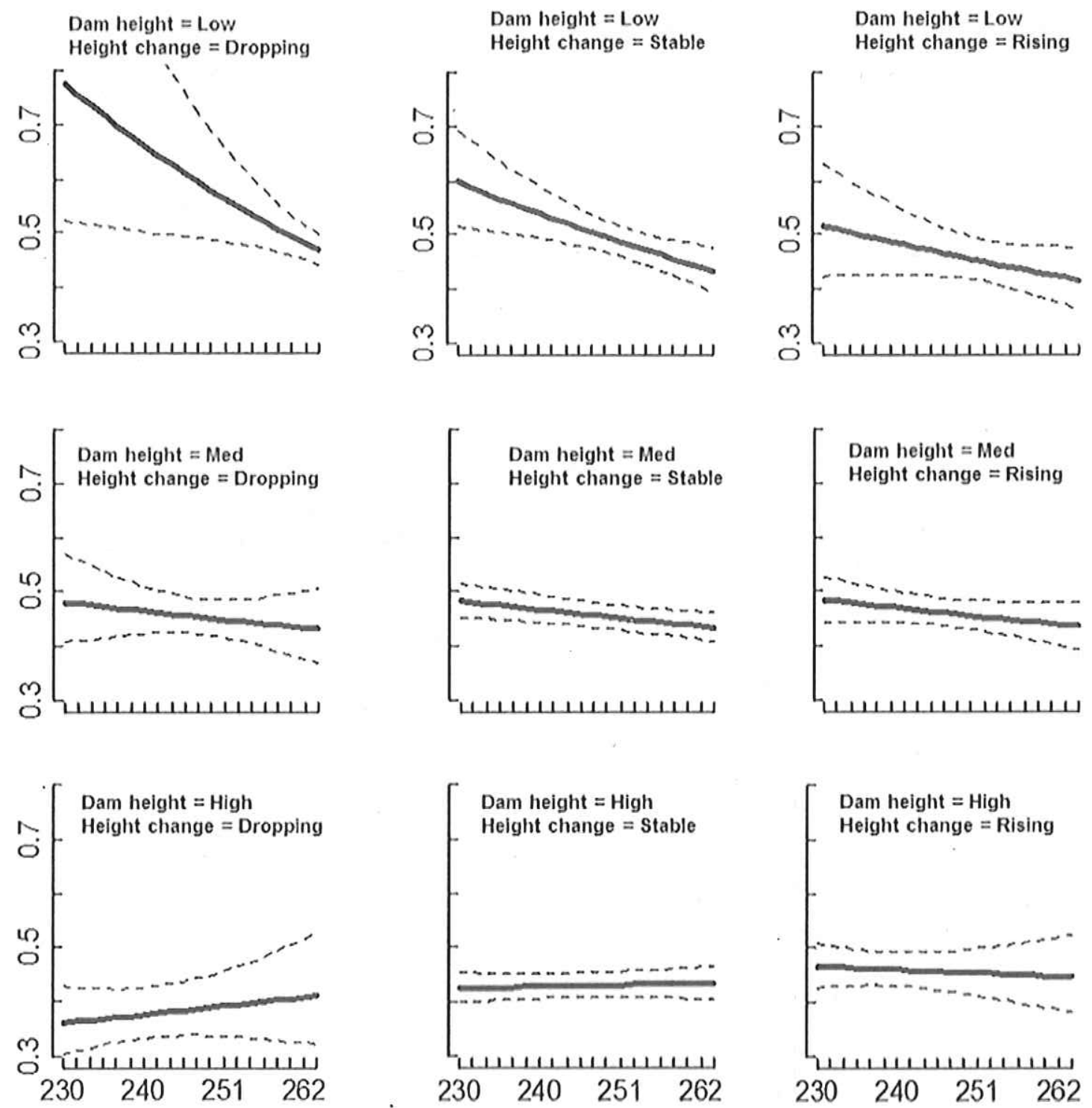

Degree months

following refilling in Lake Sakakawea on the Missouri River. In consideration of these findings, we would have expected our investigation of annual drivers and variability of Macquarie perch growth and year-class strength to align with the primary hydrological variables associated with the refilling phase of the lake, (i.e., increasing water levels and a high rate of rising levels). However, while the effects of dam height, change in dam height, temperature, and their interactions were the covariates considered the most important in explaining fish growth, years of low and receding lake levels during years of lower temperatures were predicted to promote the highest growth. Interestingly, increased recruitment strength also aligned with years of low lake levels, with the strongest year classes present during the year prior to, and first years of, the refilling phase.
While predictions of highest growth during years of low water temperatures is not surprising considering the species' natural occupancy of cool, upland streams (Lintermans 2007), the apparent negative correlation between high growth and year-class strength with lake levels during the refilling period was unexpected. We assumed that a repeated trophic upsurge would occur and continue throughout the refilling period of the lake coupled with a relatively stable temperature (in reference to the predictor variable of temperature and its interaction with lake level). Furthermore, Gray et al. (2000) reported the condition of spawning Macquarie perch to be positively correlated to lake levels during the stable period of Lake Dartmouth (1991-1997), even though fluctuations in dam height during this period were comparatively small. $\Lambda$ possible cause of reduced growth and year-class strength 
Fig. 8. Mean ( \pm SE) number of Macquarie perch collected (fish per gill net) during each of the netting surveys of Lake Dartmouth from 2010 to 2013. Mean number of fish collected during surveys undertaken in 1999 and 2000 are also included for reference (data from Victorian Inland Fisheries). The letters $a$ and $b$ represent significant differences between annual CPUE values.

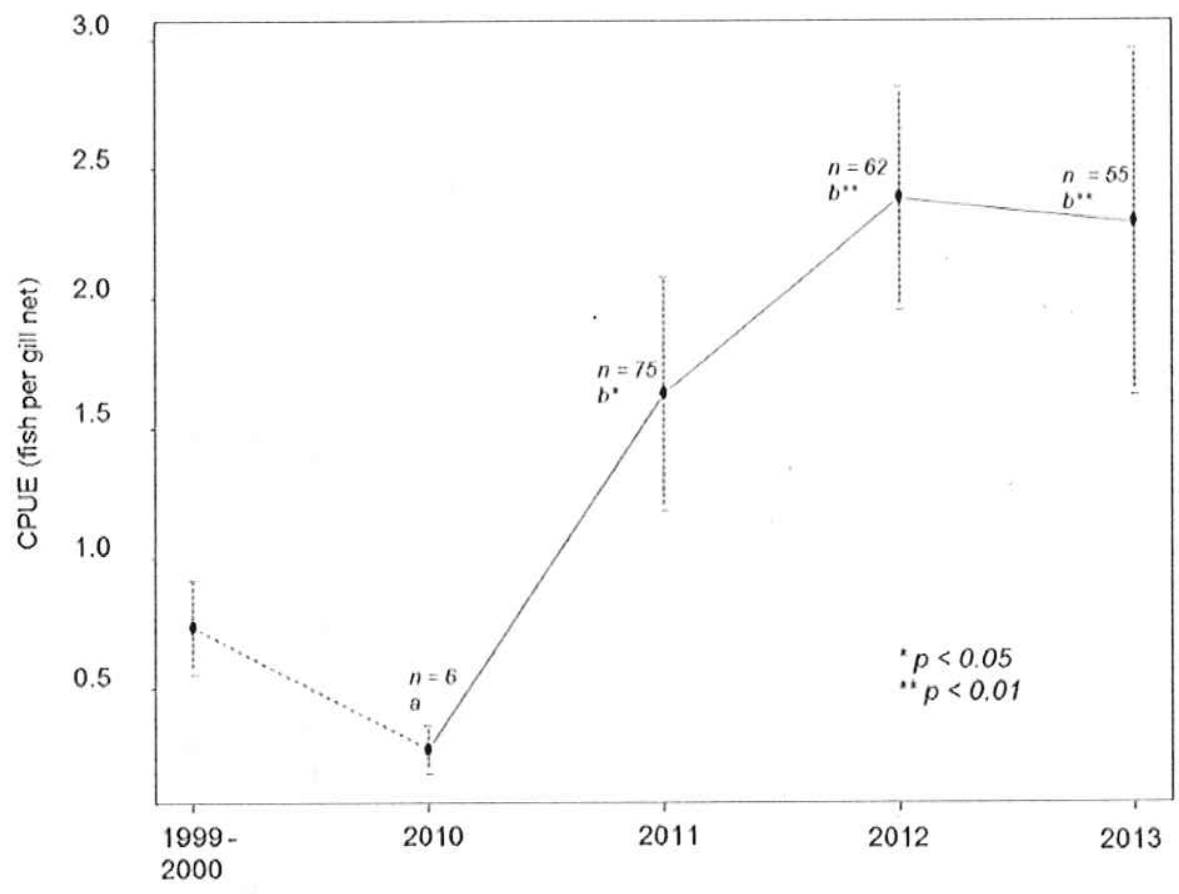

Sample year

in the latter period of the refilling phase may be due to increased intraspecific competition for prey and (or) habitat. Specifically, we propose the first years of the refilling period favoured the highest growth rates because of a combination of increased resources (the hypothesized trophic upsurge) and low Macquarie perch abundance (therefore low intraspecific competition). The resulting rapid expansion in Macquarie perch abundance then led to increased intraspecific competition in subsequent years. Intraspecific competition for resources is the most common factor driving density dependence, a common and important mechanism in the regulation of fish populations that is most effective at high population densities (Jonsson et al. 1998; Lorenzen and Enberg 2001). Furthermore, density-dependent processes such as growth, survival, and reproduction are often compensatory if their rates change in response to variation in population density, such that population growth rates are slowed at high densities and increase at low densities (Grenouillet et al. 2001; Lorenzen and Enberg 2001). Compensatory density dependence may therefore be a plausible explanation of our finding of reduced growth and year-class strength in the final years of the refilling phase. This may also explain why we found no significant difference in fish growth between the initial filling period and the stable-declining period of the lake whereby the early population expansion may have resulted in immediate increases in intraspecific competition and subsequent growth throughout the remaining filling period.

While our data precludes any such assessment, interspecific interactions influencing Macquarie perch populations cannot be excluded. Further investigation of such interactions, particularly between Macquarie perch and the exotic species goldfish (Carmssius auratus), (arp (Cyprinus carpio), and brown trout (Salmo trutta), which are abundant in the lake (Douglas et al. 2002), would be of particular interest.

Our results imply an intrinsic link between growth and recruitment success. This is based on the alignment between increased juvenile Macquarie perch growth and year-class strength reported in this and previous studies on lacustrine trophic upsurge (Hendrickson and Power 1999; Albrecht et al. 2009; Scarnecchia et al. 2009). At a conceptual level, these findings adhere to aspects of the growth-mortality hypothesis, whereby mortality of early life stages of fish is often growth-dependent, with many studies demonstrating early growth can result in substantial fluctuations in year-class strength (e.g., Campana 1996; Houde 1997; Islam et al. 2010). There may of course be alternative or additional factors governing both growth and recruitment success. Firstly, the increased growth of Macquarie perch during the first years of the refilling period may simply be a result of an increase in energyrich prey items during this period. While this study did not assess the diet of Macquarie perch during this time, previous studies in Lake Dartmouth have found Macquarie perch diets to be dominated by terrestrial arthropods and annelids during rising water levels and cladocerans during recession phases (Cadwallader and Douglas 1986). These findings of Cadwallader and Douglas (1986) suggest the predicted changes in Macquarie perch growth during the refilling period are unlikely to be a result of changes in prey composition.

Secondly, it is likely that the riverine conditions during spawning play a major role in recruitment success for this species. Lacustrine populations of Macquarie perch rely on accessing riverine habitats for spawning during spring (Cadwallader and Rogan 1977; Douglas et al. 2002; Broadhurst et al. 2013). The presence of annual year classes since dam construction reported in this study confirms earlier reports that the species spawns each year irrespective of riverine conditions (Tonkin et al. 2010). Nevertheless, varying year-class strength may also be a reflection of temporal variability in riverine conditions relating to hydraulic, hydrological, and temperature variables, which have been demonstrated to influence recruitment strength in other Australian percichthyids (e.g., Mallen-Cooper and Stuart 2003). Our results 
Fig. 9. Length (left) and predicted Age (right) frequency distribution of Macquarie perch collected during netting surveys of Lake Dartmouth from 2010 to 2013. Ages of all Macquarie perch were derived using length-based predictions of the Gompertz growth model.
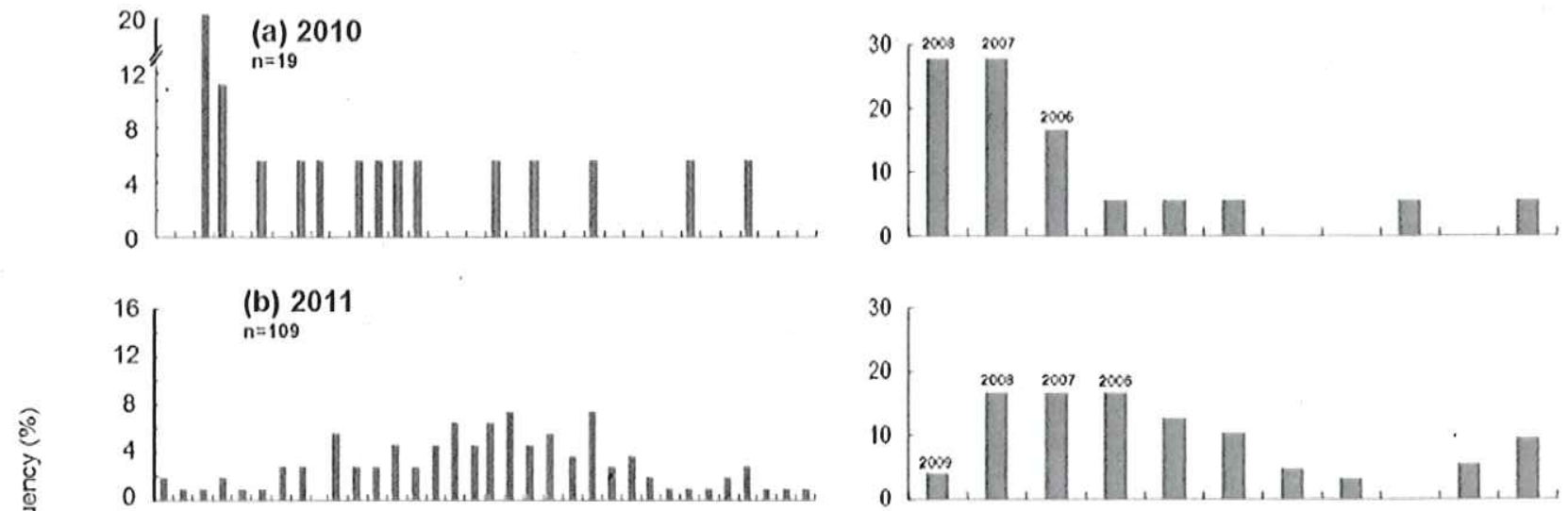

\section{(c) 2012}
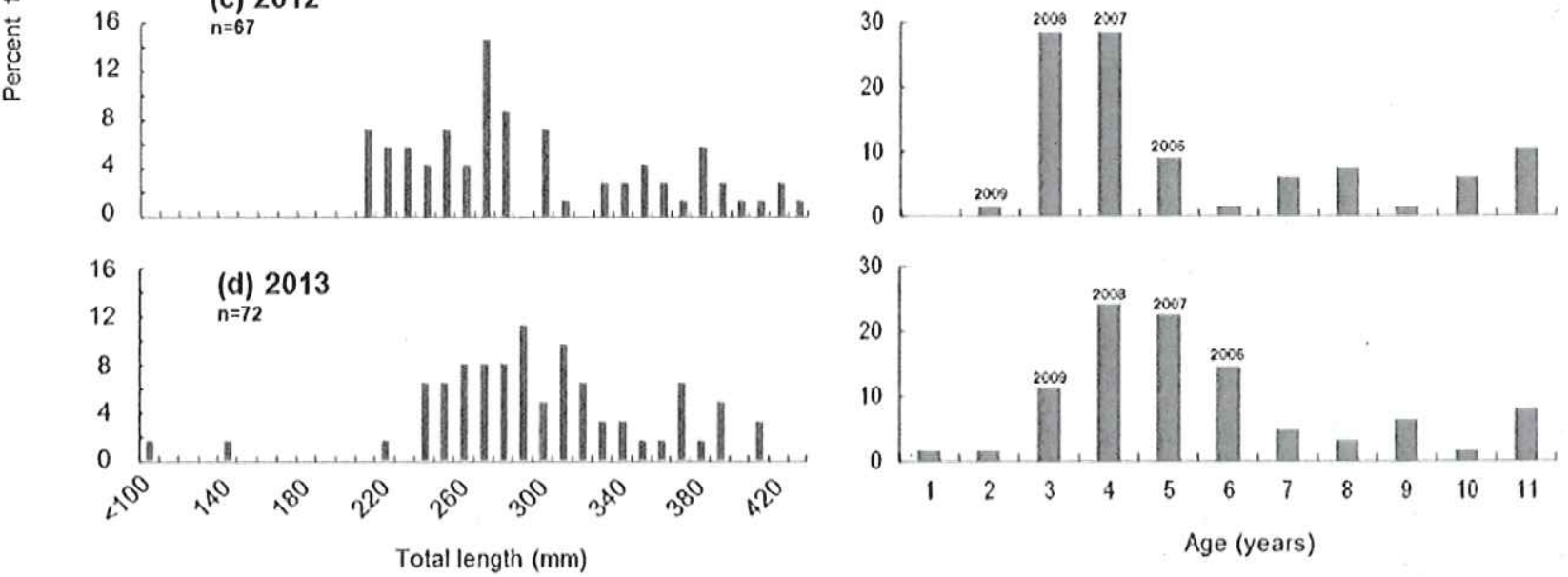

indicated the strongest year classes occurring during the refilling period (2008 and 2009) were years of low lake levels, low-moderate spring inflows, and above average spring temperatures (Murphy and Timbal 2008; Tonkin et al. 2010). It is therefore likely that one or a combination of riverine variables has contributed to increased recruitment strength of Macquarie perch in Lake Dartmouth. Further investigation into riverine variables governing recruitment strength of Macquarie perch is required to better understand the mechanisms driving recruitment success of the species.

Our results suggest lacustrine populations of Macquarie perch are relatively robust. They are long-lived (up to 26 years of age), recruit every year, and are capable of rapid expansions in population size. Gido et al. (2000) suggested native fish in an impounded river either resist or are resilient to stochastic events (such as hypoxia, turbid flows, water fluctuations, and invasion by introduced species) because most large river fishes have adapted to highly variable riverine environments. However, many riverine species, including other populations of Macquarie perch, do not persist beyond the initial phases of reservoir filling and population expansion. In most cases, it seems likely that densityindependent factors such as loss of spawning or nursery areas (Hendrickson and Power 1999), predation by exotic species (Cambray 2003), disease (Langdon 1989; Lintermans 2007), loss of connectivity to adjoining populations (e.g., Petts 1984), and overexploitation by commercial and (or) recreational fishing (Cadwallader and Rogan 1977) may have played a role in extirpating populations. Our find- ings suggest it is likely that one or a combination of these factors contributed to the disappearance of other lacustrine populations of Macquarie perch, rather than changes in lake productivity alone.

While the declime of riverine fish populations occupying large reservoirs has been well documented (e.g., Hendrickson and Power 1999), there are limited investigations of re-expansion opportunities and the mechanisms by which this can occur. The results of our study suggest that extended periods of low lake levels followed by rapid inundation events may enhance growth and recruitment opportunities for the Lake Dartmouth population of Macquarie perch into the future. Climate change predictions for southeastern Australia are for an increased likelihood of protracted drought and rapid refilling events (Morrongiello et al. $2011 b$ ). Therefore, despite the prediction that future climate change will be detrimental for remnant riverine populations of Macquarie perch (Balcombe et al. 2011), the future of this lacustrine population may be enhanced provided any such benefits are not countered by our predictions of reduced growth under higher temperatures. Similarly, Morrongiello et al. (2011a) predicted growth rates of southern populations of golden perch would increase under climate change predictions as warmer conditions lengthen growing seasons and make higher latitude habitats more favourable. This emphasises the importance of recognising the conservational benefits of large reservoirs, particularly given the predicted trajectory of many riverine fish populations under climate change (e.g., Balcombe et al. 2011). 
Water level manipulation is one of the most effective methods 10 manage fish and biological production in reservoirs (Benson 1982; Scarnecchia et al. 2009), yet its use for conservation purposes has received little attention, particularly in comparison with the use of environmental flows in lotic environments (IIardie 2013). Recently, Hardie (2013) demonstrated the successful use of water level manipulation in an Australian lake to enhance spawning and recruitment of the threatened Galaxias auratus. Water level manipulation to purely enhance species of conservation importance in multipurpose reservoirs like Jake Dartmouth is difficult because of conflicting demands for power generation, flood mitigation, and irrigation (Benson 1982). Nevertheless, its use should still be considered as a viable management option for maintaining important lacustrine populations of Macquarie perch, particularly within smaller systems or under extreme circumstances, such as following several decades of high lake levels and poor recruitment.

The proper management of reservoirs is of global importance because of their prevalence in virtually all large river systems and their economic importance for recreational, commercial, and conservation purposes (e.g., Gido et al. 2000; İbner et al. 2011). This study has demonstrated that in this case, lacustrine populations of riverine fish can be re-enhanced after the population expansions associated with initial reservoir filling provided access and conservation status of adjoining riverine habitats is maintained. This has important implications for the conservation and management of relict populations of riverine fish.

\section{Acknowledgements}

We thank the many people who contributed to this project, in particular, Peter Liepkalns of Goulburn-Murray Water; Justin O'Mahony, Andrew Pickworth, and Glen Johnson for field assistance; Joanne Kearns, Claire Hollier, and Deb Cross for laboratory and database assistance; John Douglas and Taylor Hunt for collection and provision of early fisheries survey data; and Charles Todd for constructive discussion and reviews of the manuscript. This work was funded by the Department of Tnvironment and Primary Industries, Victoria. All work was carried out under the Victorian Fisheries permit RP827, ARI Animal Ethics Committee approval 08/23, and II'ora and liauna Guarantee Act permit No. 10005913.

\section{References}

Albrecht, M., Caramaschi, F., and Horn, M. 2009. Population responses of two omnivorous fish species to impoundment of a Brazilian tropical river. Hydrobiologia, 627(1): 181-193. doi:10.1007/s10750-009-9727-7.

Anderson, J: Morison, $\Lambda$, and Ray, D. 1992. Validation of the use of thin sectioned Otoliths for determining the age and growth of Golden Perch, Macquaria ambigua (Perciformes: Percichthyidae), in the Jower Murray-Darling Basin, Australia. Mar. Ireshw. Kes. 43(5): 1103-1128. doi:10.1071/M1\%921103.

Appleford, P., Anderson, T.A., and Gooley, G.J. 1998. Reproductive cycle and gonadal development of Macquarie perch, Macquaria australasica Cuvier (Percichthyidac), in Lake Dartmouth and tributaries of the Murray-Darling Basin, Victoria, Australia. Mar. Freshw. Res, 49: 163-169. doi:10.1071/MF97012.

Balcombe, S.R., Sheldon, I., Capon, S.J., Bond, N.K., Iladwen, W.I., Marsh, N., and Bernays, S.J. 2011. Climate-change threats to native fish in degraded rivers and foodplains of the Murray-Darling Basin, Australia. Mar. Freslıw. Res. 62(9): 1099-1114. doi:10.1071/Ml11059.

Bates, D., Maechler, M., and Bolker, B. 2011. Ine4: linear mixedeffects models using SA classes fonline]. Available from http://CRAN.K-project.org/package:Ine4.

Baxter, R.M. 1977. Finvironmental effects of dams and impoundments. Annu Rev. licol. Syst. 8: 255-283. doi:10.1146/annurev.es.08.110177.001351

Bayley, P.B. 1991. The flood pulse advantage and the restoration of riverflootlplain systems. Kegul, Rivers: Res. Manage, 6: 75-86.

Benson, N.G. 1982. Some observations on the ecology and fish management of reservoirs in the United States. Can. Water Res. J. 7(1): 2-25.

Bond, N., Lake, P.S., and Arthington, A. 2008. The impacts of drought on fresh water ecosystems: an Australian perspective. Ilydrobiologia, 600(1): 3-16.

Broalhurst, B.T. Libner, B.C., Lintermans, M., Thiem, J.1), and (lear, K.C. 2013. Jailbreak: a fishway releases the endangered Macquarie perch from confinement below an anthropogenic barrier. Mar. Freshw. Res. 64(9): 900-908. doi:10.1071/Ml12245.
Burnham, K.P., and Anderson, D.R. 1998. Model selection and inference: a practical information-theoretic approach. Springer-Verlag, New York.

Cadwallader, P.I. 1981. Past and present distributions and translocations of Mac quarie Perch Macquaria austrulasica (Pisces: P'ercicthyitlae), with particular reference to Victoria. Proc. R. Soc. Victoria, 93: 23-30.

Cadwallader, P.L, and Douglas, J. 1986. Changing food habits of Macquaric Perch, Macquaria australasica Cuvier (Pisces: Percichthyidae), during the initial filling phase of lake Dartmouth, Victoria. Aust. J. Mar. Freshw. Res, 37: 647-657. doi:10.1071/M19860647.

Cadwallader, P.L, and Rogan, P.L. 1977. The Macquarie perch, Macquaria australasio (Pisces: Percichthyidac) of lake Fildon, Victoria. Aust. J.Ecol. 2: 409-418. doi:10. $1111 / j .1442-9993.1977 .1101156 x$

Cambray, J.^. 2003. The global inpact of alien trout species - a review; witl reference to their impact in South Africa. Afr. J. Aquat. Sci. 28(1), 61-67. doi:10.2989/16085914.2003.9626601.

Campana, S.E. 1996. Year-class strength and growth rate in young Atlantic cod Gadus morhua. Mar. Fcol. Prog. Ser. 135: 21-26. doi:10.3354/meps135021.

Cowx, I.G. 1998. Stocking and introduction of fish. Fishing News Books, Black. well Science, Oxford.

Cowx, I.G., O'Grady, K.T., Welcomme, R.L., and Bartley, D.M. 1998. Current ap proaches to the enhancement of fisheries. Fish. Manage. Ecol. 5: 351-382 doi:10.1046/j.1365-2400.1998.550351.x

Douglas, J., Giles, A and Strongman, R. 2002, lake Dartmouth multi-species fishery assessment. Marine and lireshwater Resources Institute lireshwater Fisheries Report No. 02/2.

Ebner, B.C., Lintermans, M., and Dunford, M. 2011. A reservoir serves as refuge for adults of the endangered Macquarie perch. Jakes Reserv. Res. Manage. 16 : 23-33. doi:10.1111/j.1140-1770.2011.00463.x.

Geraldes, A.M., and Boavida, M.J. 1999. Limnological comparison of a new reser voir with one almost 40 years old which had been totally emptied and re filled. Lakes Reserv. Res. Manage. 4(1-2): 15-22.

Gido, K.B., Matthews, W.J., and Wolfinbarger, W.C. 2000 . Long-term changes in a reservoir fish assemblage: stability in an unpredictable environment. Fcol Appl. 10(5): 1517-1529. doi:10.1890/1051-0761(2000)010|1517:LIC:IAR|2.0.CO)2.

Gray, S.C., De Silva, S.S., Ingram, B.A., and Gooley, G.J. 2000. Effects of river impoundment on body condition and reproductive performance of the Aus. tralian native fish, Macquarie perch (Macquaria australasica). Iakes Reserv. Res. Manage, 5: 281-291. doi:10.1046/j.1440-1770.2000.00122x.

Grenouillet, G., Hugueny, B., Carrel, G.A., Olivier, J.M., and Pont, 1). 2001. Large scale synchrony and inter-annual variability in roach rectuitment in the Rhône River: the relative role of climatic factors and density-dependent processes. Freshw. Biol. 46(1): 11-26. doi:10.1046/j.1365-2427.2001.00637.x

Grimard, Y., and Jones, H.G. 1982. Trophic upsurge in new reservoirs: a model fo total phosphorus concentrations. Can. J. Yish. Aquat. Sci. 39(11): 1473-1483. doi: $10.1139 /[82-199$.

Hardic, S.A. 2013. Hydrological manipulation to assist spawning of a threatened galaxiid fish in a highland lake system. Mar. Freshw. Res. 64(9): 887-899. doi: $10.1071 / \mathrm{MF} 12197$

Hardic, S.A., White, R.W.G., and Barmuta, L.A. 2007. Reproductive biology of the threatened golden galaxias Galaxias auratus Johnston and the influence of lake hydrology. J. Fish Biol. 71: 1820-1840. doi:10.1111/j.10958649.2007.01648.x.

Harris, J.H., and Rowland, S.J. 1996. Family Percichthyidac: Australian freshwater cods and basses. In Freshwater fishes of southeastem Australia. Edited by R.M. McDowall. Reed Books, Sydncy, Australia. pp. 150-163.

Hendrickson, J.C., and Power, G.J. 1999. Changes in fish species abundance in a Missouri river main stem reservoir during its first 45 years. J. Freshw. Ecol. 14(4): 407-416. doi:10.1080/02705060.1999.9663698.

Houde, E.D. 1997. Patterns and trends in larval-stage growth and mortality of telcost fish. J. Fish Biol. 51: 52-83. doi:10.1111/j.1095-8649.1997.tb06093.x.

Hunt, T.1., Allen, M.S., Douglas, J., and Gason, A. 2010. Evaluation of a Sport Fish Stocking Program in Lakes of the Southern Murray-Darling Basin, Australia. N. Am. J. Fish. Manage. 30(3): 805-811. doi:10.1577/M09-207.1.

Hunt, T.I., Douglas, J.W., Allen, M.S., Gwinn, D.C., Tonkin, Z., Lyon, J., and Pickworth, A. 2011. Evaluation of population decline and fishing sustainabil ity of the endangered Australian freshwater fish Macquaria australasica. Fish. Manage. Ecol. 18(6): 513-520. doi:10.1111/j.1365-2400.2011.00808.x.

Ingram, B, and Gooley, G. 1996. Hormone-induced spawning of the threatened Macquaric perch (Macquaria australasica): an Australian native freshwater fish. In Developing and sustaining world fisheries resources: the state of science and management. Edited by D.A. Hancock and J.P. Beumer. Proceed ings Vol. 1. pp. 97

Ingram, B.., Douglas, J.W., and Lintermans, M. 2000. Threatened fishes of the world: Macquaria australasica Cuvier, 1830 (Percichthyidac). Environ. Biol Fishes, 59: 68.

Irz, P., Odion, M., Argillier, C., and Pont, D. 2006. Comparison between the fish communitics of lakes, reservoirs and rivers: can natural systems help define the ecological potential of reservoirs? Aquat. Sci. 68: 109-116. doi:10.1007) \$00027-005 0812-3.

Islam, M.S., Ueno, M., and Yamashita, Y. 2010. Growth-dependent survival mechanisms during the early life of a temperate seabass (Latcolabrax japonicas): ficl test of the 'growth-mortality' hypothesis. Fish. Oceanogr. 19: 230-242. doi: 10.1111/j.1365-2419.2010.00539.x

Jonsson, N., Jonsson, B., and Hansen, L.P. 1998. The relative role of density 
dependent and density-independent survival in the life cycle of Atlantic salmon Salmo salar. J. Anim. Licol. 67(5): 751-762. doi:10.1046/j.1365-2656.1998. 00237.x.

Kruk, A., and Penczak, T. 2003. Impoundment impact on populations of facul. tative riverine fish. Int. J. Iimnol. 39: 197-210. doi:10.1051/1imn/2003016.

langdon, J.S. 1989. Experimental transmission and pathogenicity of epizootic haematopoietic necrosis vinus (LiINV) in redfin perch, l'erea fluviatilis L., and 11 other teleosts. J. Fish Dis. 12(4): 295-310. doi:10.1111/j.1365-2761.1989.tb00318.x.

Iintermans, M. 2007. lishes of the Murray-Darling Basin: an introductory guide. Murray-Parling Basin Commission, Canberra.

Lintermans, M. 2012. Managing potential impacts of reservoir enlargement on threatened Macquaria australasica and Gadopis bispinosus in southeastern Aus. tralia. Fndang. Species Res. 16: 1-16. doi:10.3354/esro0382.

Lobón-Cerviá, J. 2014. Recruitment and survival rate variability in fish populations: density-dependent regulation or further evidence of envirommental determinants? Can. J. Fish. Aquat. Sci. 71(2): 290-300. doi:10.1139/cjfas-20130320.

Iorenzen, K., and Fnberg, K. 2002. Density-dependent growth as a key mechanism in the regulation of fish populations: evidence from among-population comparisons. Proc. R. Soc. B Biol. Sci. 269: 49-54. doi:10.1098/rspl).2001.1853.

Mallen-Cooper, M., and Stuart, I.G. 2003. Age, growth and non-flood recruitment of two potamodromous fishes in a large semi-arid//emperate river system. River Res. Appl. 19: 697-719. doi:10.1002/rra.714.

Mims, M.C., and Olden, J.D. 2013. lish assemblages respond to altered flow regimes via ecological filtering of life history strategies. Freshw. Biol. 58(1): 50-62 doi: $10.1111 /$ fwb. 12037

Morrongiello, J.R., Crook, D.A., King, A.J., Ransey, D.S.I., and Brown, P. $2011 a$. Impacts of drought and predicted effects of climate change on fish growth in temperate Australian lakes. Global Change Biol. 17:745-755. doi:10.1111/j.13652486.2010.02259.x

Morrongiello, J.R., Bealty, S.J., Bennett, J.C., Crook, D.A., Ikedife, D.N.E.N., Kennard, MJ. Kerezsy, J Jintermans, M. McNeil, D.G., Pusey, B.J., and Rayner, T. 2011b. Climate change and its implications for Australia's freshwa. ter fish. Mar. Freshw. Res. 62(9): 1082-1098. doi:10.1071/MF10308.

Murphy, B., and Timbal, B. 2008. $\Lambda$ review of recent climate variability and climate change in southeastern Australia. Int. J. Climatol. 28: 859-879. doi 10.1002/joc.1627.

Paukert, C.P., and Fisher, W.I. 2001. Spring movements of paddlefish in a prairie reservoir system. J. Jireshw. Ecol. 16(1): 113-124, doi:10.1080/02705060.2001 9663794.

Petts, G.E. 1984. Impounded rivers: perspectives for ecological management. Wiley, Chichester.

Poff, N.L, Olden, J.D., Merritt, D.M., and Pepin, D.M. 2007. Homogenization of regional river dynamics by dams and global biodiversity implications. Proc
romention NatI. Acad. Sci. U.S.A. 104: 5732-5737. doi:10.1073/pnas.0609812104. PMII): 17360379.

$\mathrm{K}$ Development Core Team. 2005. $\mathrm{K}$ : a language and environment for statistical computing lonlinel. R Foundation for Statistical Computing, Vienna, Austria Available from http://www.R-project.org.

Robarts, R.D., Tohary, T., Jarvis, A.C., Pais-Madeira, C.M., Sephton, I.M., and Combrink, S. 1992. Phytoplankton and zooplankton population dynamics and production of a recently formed African reservoir. llydrobiologia, 237: and production of a recently for $10.1007 / \mathrm{BF} 00008427$.

Scamecchia, D.L., Ryckman, L1., Lim, Y., Miller, S.E., Schmilz, B., Power, G.J. and Shefstad, S. 2009. Riverine and reservoir influences on year clas strength and growth of Upper Great Plains paddlefish. Rev. Fish. Sci. 17(2) 211-266. doi:10.1080/10641260802621791.

Stuart, I.G, 2006. Validation of otoliths for determining age of golden perch, : longlived freshwater fish of Australia $N$. Am) J. Fish Manage 26: 52-55. doi:10.1577/M05-077.1.

Tonkin, Z., King, A.J., and Robertson, A.I. 2008. Validation of daily increment formation and the effects of different temperatures and feeding regimes on short-term otolith growth in Australian smelt Retropinna semoni. Ficol. Freshw. Fish, 17: 312-317. doi:10.1111/j.1600-0633.2007.00283.x.

Tonkin, Z., Lyon, J.P., and Pickworth, A. 2009. An assessment of spawning stocks, reproductive behaviour and habitat use of Macquarie Perch Macquaria austrulasica in Lake Dartmouth, Victoria. Arthur Kylah Institute for linviron mental Research. Tecinical report series No. 188. Department of Sustainabil. ity and Environment, Heidellerg, Victoria.

Tonkin, Z., Lyon, J., and Pickworth, A. 2010. Spawning behaviour of the endan gered Macquarie Perch Macquaria australasica in an upland Australian river. Licol. Manage. Restor. 11(3): 223-226, (loi:10.1111/j.1442-8903.2010.00552.x. 